\title{
Mental health implications of detaining asylum seekers: systematic review
}

Katy Robjant, Rita Hassan and Cornelius Katona

\section{Background}

The number of asylum seekers, refugees and internally displaced people worldwide is rising. Western countries are using increasingly restrictive policies, including the detention of asylum seekers, and there is concern that this is harmful.

\section{Aims}

To investigate mental health outcomes among adult, child and adolescent immigration detainees.

\section{Method}

A systematic review was conducted of studies investigating the impact of immigration detention on the mental health of children, adolescents and adults, identified by a systematic search of databases and a supplementary manual search of references.

\section{Results}

Ten studies were identified. All reported high levels of mental health problems in detainees. Anxiety, depression and posttraumatic stress disorder were commonly reported, as were self-harm and suicidal ideation. Time in detention was positively associated with severity of distress. There is evidence for an initial improvement in mental health occurring subsequent to release, although longitudinal results have shown that the negative impact of detention persists.

\section{Conclusions}

This area of research is in its infancy and studies are limited by methodological constraints. Findings consistently report high levels of mental health problems among detainees. There is some evidence to suggest an independent adverse effect of detention on mental health.

\section{Declaration of interest}

None.
The number of asylum seekers, refugees and internally displaced people worldwide rose to 20.8 million at the beginning of 2006. ${ }^{1}$ Western countries have increasingly resorted to policies aimed at reducing the numbers of individuals seeking residency. These 'policies of deterrence' include the reduction of access to healthcare services, education and employment as well as an increase in the practice of detaining individuals who are seeking asylum $^{2}$ and the provision of time-limited rather than permanent protection. Immigration removal centres in the UK are secure environments where asylum seekers and other categories of foreign nationals are detained. Individuals are held within these centres for an indefinite period while awaiting the outcome of administrative processes regarding their application for leave to remain in the UK. The majority are deemed by the Home Office to have exhausted their legal processes and to be 'failed asylum seekers' awaiting removal to their country of origin or to a third country. Some, however, are still in the process of legal appeal and others initiate fresh asylum claims while in detention. Another group that may be detained in these centres are foreign nationals who have completed prison sentences for offences committed in the UK and are awaiting or contesting deportation. Within the UK there is a capacity of 2557 places for immigration detainees and deportees. In 2005, a total of 29210 individuals left detention. Of these, $59 \%$ were deported from the UK. The rest were given temporary leave to remain or were granted bail to live within the community until the outcome of their claim was determined. $^{3}$

Under the 1951 United Nations Convention on the Status of Refugees, a refugee is an individual who has successfully completed the legal processes required to achieve permanent residency within the host country. Refugees are therefore not detained in immigration removal centres. Asylum seekers are entitled to recognition as a refugee if they have a well-founded fear of persecution because of race, religion, nationality, membership of a social group or political opinion. Asylum seekers have often experienced traumatic events in their country of origin.
Individuals detained within immigration removal centres could, therefore, be described as a vulnerable group particularly susceptible to the adverse effects on mental health associated with detention. According to Home Office guidelines, individuals who are experiencing mental health problems should not be detained unless there are exceptional circumstances. ${ }^{3}$

\section{Mental health of asylum seekers}

Research suggests that asylum seekers and displaced persons worldwide report high rates of pre-migration trauma, ${ }^{4}$ and therefore of trauma-related mental health problems. In a metaanalysis of worldwide studies investigating the mental health of refugees (including asylum seekers and displaced persons), Porter \& Haslam found high rates of psychopathological disorder among refugees worldwide compared with non-refugee control groups. ${ }^{5}$ There is therefore consistent evidence to suggest that asylum seekers and refugees have higher rates of mental health difficulties than are usually found within the general population. The process of seeking asylum in Western countries places additional demands on this group. These include stressful legal processes. In an Australian study comparing post-migratory stress in refugees, asylum seekers and immigrants, Silove et al showed that the 'refugee determination process' (including interviews by immigration officials) was regarded as stressful by asylum seekers. ${ }^{6}$ In addition, a Dutch study showed that longer asylum processes result in increased risk of psychiatric disorder. ${ }^{7}$ The authors also reported increased anxiety, depression and somatoform disorders in individuals who had lived in The Netherlands for more than 2 years compared with refugees who had arrived within the preceding 6 months. Consistent with these findings was the observation of high rates of post-traumatic stress disorder (PTSD) symptoms in both groups. Post-migratory stressors seem, therefore, to be negatively affecting this population, who are already vulnerable to mental health difficulties as a result of their previous exposure to traumatic events. 


\section{Asylum seekers in detention}

Asylum seekers who are detained in the host country experience a further and more specific set of stressors, reflecting the detention process itself and the detention centre environment, which may adversely affect their mental health status. These include loss of liberty, uncertainty regarding return to country of origin, social isolation, abuse from staff, riots, forceful removal, hunger strikes and self-harm. ${ }^{8-10}$ Given the well-documented vulnerability of asylum seekers as a result of experience of trauma prior to arrival, a number of clinicians have expressed concern that detention increases mental health difficulties in adult and child asylum seekers, and have called for an end to such practices. ${ }^{11-13}$ This conflicts with current government policy aimed at reducing numbers of asylum seekers. ${ }^{2}$ The practice of detaining asylum seekers is therefore currently a prominent and contentious issue in terms of policy, health and social care. These issues are outlined in more depth by Steel \& Silove. ${ }^{14}$

The aim of this review was to identify studies that have investigated the impact of immigration detention on the mental health of detainees held in Australia, the UK and the USA. Studies that investigated the impact of detention on children and adolescents were included in the review. The results of these studies were reviewed in order to consider whether there is evidence for an association between increased prevalence and severity of mental health problems and immigration detention.

\section{Method}

\section{Search strategy}

The search terms 'asylum', 'detention', 'depression', 'anxiety' and 'PTSD' were used to identify relevant studies in the databases PsycINFO, PubMed, PubCentral and PILOTS, with a cut-off date of April 2007. In addition, manual searches of the reference lists of relevant studies were used to identify further relevant studies.

\section{Inclusion criteria}

We included all studies that reported quantitative or qualitative measures of mental health for children, adolescents or adults who were either currently detained or who had previously been detained in immigration detention or removal centres in Australia, the UK or the USA. Qualitative studies that described consecutive case series of more than two cases were included.

\section{Exclusion criteria}

Single-case studies were excluded. The search strategy outlined above yielded several commentaries and letters, which were also excluded, as were review papers, although relevant studies identified from the references cited within these commentaries were included. Studies conducted in other countries were excluded.

\section{Selected studies}

The above search strategy was carried out by the first author (K.R.) and resulted in the identification of 49 articles (including studies that met the inclusion criteria as well as commentaries, letters, case studies and studies that took a legal or sociological stance). Uncertainties about whether individual studies met the inclusion criteria were resolved by discussion between the authors. This selection process resulted in ten studies being identified for detailed review.

\section{Results}

Studies that met the selection criteria can be grouped into those reporting on case series and those comparing currently or formerly detained asylum seekers with a comparison group. The design, measures, results and findings are summarised in Table DS1.

\section{Case series}

Bracken \& Gorst-Unsworth and Arnold et al have both described opportunistic case series of asylum detainees in the UK. ${ }^{15,16}$ They described therapeutic and assessment work undertaken by clinicians within organisations working with refugees and asylum seekers: the Medical Foundation for the Care of Victims of Torture (www.torturecare.org.uk) and Medical Justice (www.medicaljustice.org.uk). Although the studies took place 15 years apart, both describe manifest psychological or psychiatric difficulties experienced by detainees with whom the authors had worked. Bracken \& Gorst-Unsworth described the evidence leading to their clinical conclusion that there was a high level of psychological disturbance and a consistent pattern of symptoms in each of ten detainees, all of whom had previously experienced torture. ${ }^{15}$ This included intense fear and anxiety, sleep disturbance and nightmares, irritability and frustration, as well as profound hopelessness and concerns about their own mental health. The authors did not report the use of any standardised ratings, which compromises the validity of their results. They described six of the individuals as expressing anxiety regarding their mental health, and all ten reporting depressed mood, appetite loss and other physical problems. Four detainees had suicidal ideation, two of whom had made actual suicide attempts. Although these qualitative impressions are useful in indicating emotional problems experienced by detained persons, a detailed case study is provided for only one individual and the extent to which these experiences are generalisable to other detainees is not addressed.

More recently, Arnold et al reported the results of the medical assessment of 56 consecutive patients who were either in detention or had been recently released: $59 \%$ fulfilled ICD-10 criteria for PTSD or depression. ${ }^{16}$ Adherence to a specified diagnostic tool increases the validity of these findings but it is unclear how representative their sample is of the asylum detention population as a whole. These reports of high levels of mental health problems among detainees are consistent with a participant-observer account reported by Sultan \& O'Sullivan, an Iraqi doctor who had been detained in an Australian immigration centre and a clinical psychologist working at the same facility. ${ }^{17}$ These authors suggested that psychological difficulties observed among detainees increase through successive stages, triggered by negative outcomes on asylum decisions. Their descriptive reports are supported by a survey of 33 detainees (predominantly men), using a semistructured interview. ${ }^{17}$ Individuals who had been detained for over 9 months were invited to participate; the findings represent $89 \%$ of this target population and are therefore highly representative of this subsample of detainees. Among those interviewed, 85\% reported chronic depressive symptoms, 65\% reported suicidal ideation, 39\% were experiencing paranoid delusions and $21 \%$ showed signs of psychosis. In addition, 57\% of participants required psychotropic medication. Information regarding the nature of the measures used to rate symptoms was not provided.

The findings from these case series provide clear documentary evidence of serious mental health problems among detainees. However, as collections of case studies they are subject to selection bias 
and may not be representative of detainees, many of whom do not come into contact with these specialist organisations. In addition, the association between detention experience and poor mental health is confounded by high rates of previous trauma exposure in the detainees studied. The extent to which detention can be described as having an independent negative impact on mental health is therefore not fully clarified by these reports. However, the high rate of disorder reported compared with the general refugee literature and the description of increasing symptom severity with increasing time in detention at least suggest an independent or confounding role for the detention process. ${ }^{17}$

\section{Systematic studies}

More systematic methods were used in a small number of studies, mainly carried out in Australia. Thompson et al compared a group of 25 detained Tamil asylum seekers from Sri Lanka with a community-based group of Tamil asylum seekers. ${ }^{18}$ They also compared findings with those in non-detained refugees and migrants from the same ethnic background. The comparison group data came from a previous study in which levels of trauma and symptoms had been investigated. ${ }^{19}$ The authors used self-report measures commonly applied in research with asylum seekers and refugees: the Harvard Trauma Questionnaire, ${ }^{20}$ the Depression, Anxiety and Somatisation scales of the Hopkins Symptom Checklist-25, ${ }^{21}$ as well as the Four Measures of Mental Health Panic Scale, ${ }^{22}$ and a measure of exposure to post-migration stressors designed for the study. Respondents in the detainees group were more depressed and suicidal, and experienced more extreme post-traumatic panic and anxiety as well as increased somatic distress. An additional important finding was that detained participants had been exposed to a greater number of trauma experiences. However, levels of pre-migration trauma did not account entirely for the differences. The authors concluded that this suggests that the conditions of detention also contributed to the mental health difficulties experienced by detainees. Although the descriptive data are useful in demonstrating that detention was associated with increased incidence of mental health difficulties on all measures, it is difficult to draw conclusions from this in the absence of any details regarding the statistical techniques used or the results of multivariate analyses.

In a study based on a population of Mandaean refugees in Australia, Steel et al found further evidence for a relationship between detention and mental health problems. ${ }^{23}$ Using snowball sampling techniques, the authors recruited 241 participants (constituting an estimated $60 \%$ of the Mandaean refugee population living in Sydney) and assessed the prevalence of PTSD and of major depressive disorder as well as stress factors which were related to past trauma, detention and temporary protection. Clinical measures included the Harvard Trauma Questionnaire and the Hopkins Symptom Checklist-25. The mental and physical health component summaries of the Medical Outcomes Study Short Form were used to measure mental and physical health status and disability. ${ }^{24}$ The authors used the Detention Symptom Checklist to assess adverse effects of particular experiences associated with detention. ${ }^{25}$ The authors also compared the effects of being granted a temporary protection visa $v$. a permanent protection visa. Temporary protection is a less secure status, requiring the holder to demonstrate a need for continued protection every 3-5 years. Further constraints applied to temporary protection visa holders include restricted access to employment and educational opportunities. ${ }^{26}$ Within this sample, $58 \%$ held temporary visas, whereas $42 \%$ held permanent visas; $62 \%$ of the sample had a history of asylum detention and had been released, on average, 3 years previously.
Using multivariate analyses, the authors investigated whether there was an independent effect of detention and of temporary $v$. permanent protection visa status. Time in immigration detention and temporary protection contributed independently to all three measures of mental health difficulties $(P<0.05)$, even when other significant risk factors such as trauma history, family composition, age, gender and length of residency were taken into account.

Additional univariate analyses within the group who had experienced detention showed greater levels of traumatic distress related specifically to past detention among those who had been detained for longer than 6 months compared with those who had been detained for shorter periods. A higher proportion of those who had been detained in excess of 6 months met diagnostic cut-offs for PTSD, depression and moderate to severe mental health-related disability than those who had been detained for shorter periods or who had not been detained. A parallel study by the same group investigated the same factors in Persian-speaking refugees. ${ }^{26}$ All former detainees rated detention experiences as causing serious or very serious stress. These included fears of being sent home, being told they should return home by officers in detention facilities and language difficulties (reported as causing serious or very serious stress by $95 \%$ ). In this study, $42 \%$ of participants had temporary protection visa (TPV) status and 58\% held permanent protection visas (PPVs). Temporary protection visa status included previous experience of detention for an average of 1 year, whereas holders of a PPV had not experienced detention. Univariate analyses using two-sample $t$-tests showed significantly higher scores in TPV holders compared with PPV holders on anxiety $(P<0.001)$, depression $(P<0.001)$, PTSD $(P<0.001)$ and general distress $(P=0.003)$ (as measured by the General Health Questionnaire ${ }^{27}$ ). These differences were not attributable to experience of pre-migration trauma.

Again, multivariate analyses were used to test whether postmigration factors had an independent adverse effect. Holding a TPV was the most significant predictor of PTSD. In order to explore further the negative impact of post-migration stress, the number of negative detention experiences, the number of current living difficulties and current separation from spouse replaced TPV status in a second multivariate model, as the combination of these stressors were shown to have 'almost perfect collinearity' with TPV status. This second model was used to analyse the independent effects of these stressors on measures of mental health and disability, while adjusting for the effects of age, gender and pre-migration trauma experiences. Of particular interest in this review is the independent impact of detention. Past detention stressors predicted PTSD $(\beta=0.47, P<0.001)$ and mental healthrelated disability $(\beta=0.30, P<0.001)$, but did not predict anxiety, depression, general distress and physical health-related disability.

These studies are the first to investigate the mental health implications of detention followed by temporary compared with permanent protection. They suggest that the combination of the detention experience and continued immigration status uncertainty following release is particularly harmful to mental health. The study by Steel et al shows that the damaging effects of detention persist following release. ${ }^{23}$ The use of measures that have been used widely in refugee research in addition to measures specifically adapted for detention experiences increases the validity of findings. Administration of interviews through one native Persian speaker maximised transcultural validity. ${ }^{26}$ The use of snowball sampling techniques resulted in recruitment of a large proportion of the target populations, ${ }^{23}$ although as the authors of the study acknowledge, it is possible that more distressed individuals were more likely to participate. Studies that have targeted a specific group are useful in allowing within-group comparisons and in increasing the number of populations in which these issues have 
been addressed, although the findings from any one study may not generalise to other refugee groups from different backgrounds.

In the only longitudinal study we identified, Keller et al looked at rates of symptoms of depression, anxiety and PTSD in detained asylum seekers and compared them with rates of mental disorder at follow-up. ${ }^{10}$ Initial baseline interviews were conducted with 70 detainees (73\% of those eligible) with a median duration of detention of 5 months. Follow-up data were collected at a median of 101 days later in 61 of the original participants. Some participants had been released $(n=26)$ but the rest were still in detention. The authors used the PTSD sub-scale of the Harvard Trauma Questionnaire and the Hopkins Symptom Checklist-25 to measure anxiety and depression. Spearman correlation coefficients were used to examine the relationship between time in detention and anxiety $(r=0.34, P=0.004)$, depression $(r=0.28$, $P=0.017)$ and PTSD symptoms $(r=0.28, P=0.019)$. Consistent with findings in the Australian studies, ${ }^{23}$ time in detention was directly related to severity of symptoms. This was also consistent with subjective reports; $70 \%$ of detainees reported deterioration in their mental health while in detention. Overall, clinically significant levels of depression, anxiety and PTSD were found in a high proportion of detainees in the sample $(86 \%, 77 \%$ and $50 \%$ respectively). Independent sample $t$-tests were used to compare symptom scores from baseline at follow-up in those who had been released and those who were still detained. At baseline there was no significant difference between group scores in those who were eventually released and those still detained. The difference at follow-up was significant; however, reductions in symptoms were observed at follow-up in those who had been released $(P<0.0001)$. The repeated-measures design allows for measurement of the effect of release from detention in comparison with continued detention in two groups of detainees who did not differ at baseline. These studies consistently suggest a possible independent effect of detention on mental health.

In the first study to investigate the impact of detention within the UK, Pourgourides et al provide qualitative explanations of how detention affects people psychologically. ${ }^{9}$ In-depth interviews with 15 male former detainees as well as focus group discussions (comprising former detainees, members of detainee support and campaigning groups, professional advisors and health professionals) informed a grounded theory account of how and why mental health problems arise in this group. The results of psychiatric diagnostic interviews with the detainees were reported: 27\% were diagnosed with PTSD, 60\% with depression, 7\% with panic disorder and $7 \%$ with psychosis. Detailed qualitative findings from the study are outlined at length by the authors but are not described here. The authors highlighted a number of specific difficulties unique to the detention experience, which adversely affect mental health. The detention experience incapacitates detainees, in that it does not allow utilisation of usual coping skills, and constitutes a meaningless environment. Detainees are therefore preoccupied by time and experience extreme boredom and frustration as well as a sense of having no future. The potential for the detention environment to reactivate and exacerbate previous traumas was also raised as a theme. The authors conclude that the high incidence of hopelessness, depression and despair among detainees can be regarded as normal reactions to an abnormal situation, and detention itself as an ongoing trauma.

\section{Impact of detention on children, adolescents and their families}

Three studies that met our inclusion criteria looked at the impact of detention on children and their families. ${ }^{17,25,28}$ In addition to the observations of mental health problems in adults, the participant-observer study by Sultan \& O'Sullivan also reported on the effects on children. ${ }^{17}$ These effects were considered to be mediated through negative characteristics of the detention environment itself as well as through the impact of detention on the parents' mental well-being. Observed disturbances included separation anxiety, disruptive conduct, nocturnal enuresis, sleep disturbances (including nightmares, night terrors and sleepwalking) and impaired cognitive development. Severe symptoms of distress (including mutism, refusal to eat and drink, and stereotypical behaviours) were also reported in some cases. These reflect observations made by the authors, and unfortunately no information regarding the prevalence of these observations is reported, severely limiting the reliability of these data.

Mares \& Jureidini reported on ten consecutive referrals made to a child and adolescent mental health service in Australia from a detention centre. ${ }^{28}$ The study involved 16 adults and 20 children who were detained at the time of the study and had been in detention for 1-2 years at the time of the first interview. The study also included a follow-up interview for five families at 12 months. All participants were interviewed by child psychiatrists or allied health clinicians and consensus diagnoses were made. The authors reported that all children had at least one parent with mental health problems, but only two adults reported mental health difficulties prior to arriving in Australia. Among the 16 adults within the sample, $87 \%$ had major depression, $56 \%$ showed clinical symptoms of PTSD and $25 \%$ had a psychotic illness. Self-harm was also common $-31 \%$ had made significant repeated attempts. Among children aged less than 5 years, developmental delays were common. Out of ten such children, half had delays in language and social development. Emotional and behavioural dysregulation as well as attachment problems were observed.

Among the children in the older age range (6-17 years) mental health difficulties were extensive. All ten of these children met clinical criteria for PTSD. In addition, all ten had major depression and expressed suicidal ideation. Eight children had actually engaged in self-harm and the authors noted that a culture of self-harm existed within the detention centre. Seven had symptoms of anxiety disorder and half had persistent physical health symptoms. Children regularly reported boredom, a sense of injustice, sleep difficulties, anxiety regarding delays in educational progress and a sense of shame.

At the 12-month follow-up the well-being of the five families who were still detained had deteriorated. The authors reported that an initial improved sense of well-being among families who had been released from detention had generally not persisted. However, neither clinical diagnostic information nor outcomes from self-report measures accompanied these clinical observations in the report. In addition, the representativeness of these cases for other families held within this centre is unclear. The initial severity of the psychopathological symptoms in these children might have precipitated the initial referral to the service and their subsequent inclusion in the study.

Steel et al investigated mental health difficulties among detained families from a single ethnic group in one centre in Australia, ${ }^{25}$ by administering psychiatric interviews by telephone. The ethnic origin of the detainees interviewed was not specified in order to protect their anonymity. The study sample consisted of nearly all the members of the particular ethnic group within a single detention centre, comprising 10 families (14 adults and 20 children) out of 11 families who were eligible. Participants had been detained for a minimum of 2 years. All adult participants stated that they had experienced traumatic events prior to leaving their country of origin as well as en route to Australia. The semistructured interviews included the Structured Clinical Interview 
for DSM-IV Axis I Disorders (SCID-IV) for adults and the Schedule for Affective Disorders and Schizophrenia for Schoolage Children - Present and Lifetime version (K-SADS-PL) for children. ${ }^{29,30}$ These measures allowed assessment of prevalence of psychiatric disorder during detention as well as allowing diagnoses to be made retrospectively for the incidence of mental health difficulties prior to detention. The interviews also consisted of measures of common experiences in detention (Detention Experiences Checklist), as well as a list of nine stress symptoms taken from standard PTSD measures but focused on the detention experience itself (designed for this study): the Detention Symptom Checklist. A parenting questionnaire, again designed for the purpose of the study, was also included. All adults reported premigration trauma as well as traumatic experiences occurring in detention.

Psychiatric assessment indicated the prevalence of psychiatric disorders in adults and children to have increased markedly since the participants were detained. All adult participants were diagnosed with major depressive disorder, whereas only $21 \%$ reported symptoms (retrospectively) that would indicate a diagnosis of depression prior to detention. Two (14\%) were diagnosed in detention with severe depressive disorder with psychotic features. A large proportion (86\%) of adults were also diagnosed with PTSD while in detention $-50 \%$ of these cases were also retrospectively diagnosed with this. There was also an increase in suicidal ideation, with $93 \%$ of adults experiencing persistent suicidal ideation. Prior to detention, none of the participants had experienced persistent suicidal ideation nor had self-harmed; $36 \%$ of adults had self-harmed when assessed during detention. Overall, the authors reported a threefold increase in psychiatric problems. Parents also reported a marked decrease in their parenting capabilities since being detained. Only one adult responded positively to being 'able to care for and support children' and 'able to control the behaviour of children' while detained, whereas all participants stated that they were able to do this prior to detention.

Similarly to the results for parents, a substantial increase in psychiatric disorders was reported at the time of assessment among children. Comparison of the diagnoses made at the time of assessment while children were detained, with retrospective diagnoses for incidence of psychiatric disturbance prior to detention, revealed a tenfold increase in psychiatric difficulties among these children. All children were diagnosed with at least one psychiatric disorder at the time of assessment, the majority (80\%) exhibiting multiple disorders. While in detention, 50\% of the children were diagnosed with PTSD (with some re-experiencing symptoms being directly related to events in detention), all but one child received a diagnosis of major depressive disorder and 50\% were diagnosed with separation anxiety disorder. Oppositional defiant disorder was also common, occurring in $45 \%$ of cases. Enuresis was present in $20 \%$ of the total sample but in four out of seven children aged 6-10 years, the age range in which this disorder usually occurs. Suicidal ideation was reported by $55 \%$ of the sample and $25 \%$ had self-harmed by cutting their wrists or head banging. In contrast, prior to detention, only one child met criteria for multiple disorders (depression, PTSD and separation anxiety). Two other children were retrospectively diagnosed with either depression or separation anxiety prior to being detained.

In addition to these findings of a deterioration in mental health during detention, the use of the Detention Experiences Checklist and the Detention Symptom Checklist allowed analysis of the extent to which current difficulties were directly linked to detention experiences. All participants reported experiences of traumatic events occurring during detention. 'Sudden and upsetting memories of the time in detention' and 'images of threatening or humiliating events in detention' were reported as causing distress in all adults and in $90 \%$ of the children. Increased anger and 'feeling extremely sad and hopeless' were also reported by all adults. All of the other nine detention-related symptoms were reported as causing distress in $86-100 \%$ of adults and in $53-90 \%$ of children. Although this study is limited by the methodological problems associated with administering interviews by telephone and the possibility of recall bias, the findings suggest an overall deterioration occurring as a response both to the detention process itself and to specific detention experiences.

\section{Discussion}

Findings from these studies consistently support an association between the experience of immigration detention practices and poor mental health. This association has been demonstrated using a variety of research methods with individuals detained in varying contexts in the UK, Australia and the USA, comprising individuals of all ages and from different ethnic groups. The restriction of this review to studies in these countries means that the findings may not be applicable to the experiences of detainees in the rest of Europe.

All studies found high levels of emotional distress among individuals who were in detention or who had been previously detained. Among children, mental health difficulties in combination with developmental and behavioural problems were observed. ${ }^{17,28}$ Although in its infancy, research into the effects of detention has used increasingly sophisticated methods in order to attempt to identify and isolate the independent effects of numerous adverse circumstances on the mental health of these individuals. This has produced evidence that the findings relate in part to pre-detention trauma experiences, in addition to detention itself having an independent adverse effect on mental health.

The combination of quantitative and qualitative findings has enabled investigation of both the extent and severity of mental health problems among detainees as well as allowing meaningful contextualised interpretations of how detention affects individuals. Anxiety, depression and PTSD in particular have been observed in all of the studies, although lower prevalence rates of mental health problems such as psychosis have also been reported. ${ }^{17,25,28}$ Self-harm and suicidal ideation were also widely reported. ${ }^{15,18,28}$ Qualitative studies have suggested that psychological factors influencing the mental health of detainees include feelings of hopelessness and a sense of injustice. ${ }^{9}$ This suggests that both the psychological impact of detention as well as factors relating to the detention environment may adversely affect mental health.

Sampling methods targeting individuals who had experienced detention but had been released at the time of the study, as well as the inclusion of follow-up data, have allowed investigation of the longer-term impact of detention. Longer periods of detention are associated with worse outcomes. ${ }^{10,17,23}$ Symptoms were found to be linked to specific experiences in detention. ${ }^{25}$ Although improvement in symptoms subsequent to release has been reported, ${ }^{10}$ Steel et al found that longer periods of detention were still associated with poorer mental health outcomes 3 years following release. ${ }^{23}$ Although few studies have investigated this issue, these preliminary findings suggest that the harmful effects of detention remain, despite initial improvement following release. Further research is required to address the longitudinal impact of detention on mental health, as well as subsequent social acculturation processes. This issue is further complicated by the 
fact that release may or may not be associated with long-term security in terms of asylum decisions. Continuing uncertainty about asylum status following release appears to be an important mediator of post-release outcome. ${ }^{23,26}$

Research in this field is problematic for a number of practical and methodological reasons. Researchers report encountering difficulties in acquiring access to detained asylum seekers. This reflects the highly politicised context within which this research is undertaken. ${ }^{14}$ Many studies have relied on retrospective measures, which may be subject to recall bias. The small sample sizes recruited for many of the studies reflect some of these practical difficulties and unfortunately this limits the possibility of statistical analysis. A number of studies only report descriptive results. ${ }^{15-17,25,28}$

Methodological difficulties in measurement and sampling also limit the reliability, validity and generalisability of findings. In particular, overreporting of symptoms in order to secure a better legal outcome has been suggested as a possible source of bias in many studies. However, as acknowledged by a number of authors, this is unlikely given the anonymity of the research. In addition, asylum decisions are made on an evaluation of objective rather than subjective threat. Emphases on current subjective experiences are unlikely to influence these decisions. Furthermore, in a number of studies, participants have reported symptoms and experiences prior to detention or subsequent to release that are inconsistent with either a self-serving bias or general overreporting of distress. ${ }^{10,25}$

In terms of measurement, literacy levels, language and cultural barriers complicate findings in terms of reliability and generalisability. Extensive efforts have been made to overcome these difficulties, including using same-language speakers with experience of working with the target populations, ${ }^{26}$ or the use of measures that had been translated and back-translated ${ }^{10,23}$ and used extensively in research with asylum seekers and refugees. The use of clinical diagnostic measures in some studies has increased the validity of these results.

The use of targeted sampling of specific groups increases the validity of results for one ethnic group while limiting the generalisability of the findings to other groups. ${ }^{18,23,26}$ Measurement across groups produces the opposite effect. ${ }^{9,10,17,28}$ Where targeted sampling has occurred, a high proportion $(60 \%)$ of the estimated target sample has been reported. ${ }^{23}$ An additional sampling limitation is that a number of studies have recruited participants through agencies, which are more likely to attract distressed individuals. ${ }^{15,16,28}$ The conditions of detention vary considerably within and across countries, further limiting the generalisability of findings. In addition, the small sample sizes studied and the range and complexity of the difficulties encountered by asylum seekers before, during and after detention make it difficult to isolate independent effects. Although the effects of the detention experience have been evidenced as statistically independent from those of previous traumas, ${ }^{23,26}$ confounding variables cannot be fully controlled within the study designs used. ${ }^{23,26}$ The use of ethnically matched comparison groups has, however, been useful in attempting to minimise some of these limitations.

Despite these limitations, these studies are consistent in their findings of poor mental health among detained asylum seekers. There is growing evidence that asylum procedures are increasing the mental health difficulties of traumatised individuals who are seeking asylum in the West. Further research is required to investigate the extent to which detention has an independent toxic impact. Given the extent and severity of the mental health problems observed in detained people in three different countries, research in this area is urgently needed. Qualitative and quantitative research aimed at identifying factors that mediate this relationship is required. In addition, it is imperative that further research be conducted to ascertain the acute and longitudinal impact of such practices.

The specific nature of the effect of detention experiences on the development and maintenance of mental health problems has important wider implications for research into traumatic reactions. In particular, the effects of factors within the detention environment on the maintenance and development of symptoms and the extent to which symptoms of PTSD can be viewed as an anticipatory response in those who fear repatriation require further exploration. Research in this area has important implications for policies and attitudes regarding immigration procedures, mental health and human rights. There are a number of ethical implications for researchers and clinicians working in this area. ${ }^{14}$ The highly contentious nature of these issues results from the numerous conflicts of interest between governmental, scientific and clinical bodies. This has escalated as evidence attesting to the harmful effects of detention on mental health has accumulated, to the extent that researchers have been accused of furthering political agendas through research. ${ }^{14}$ There is a real danger that research access to people in asylum detention may be limited by concerns over the political implications of the research findings. Given the severity of mental health implications for those held in detention suggested by the studies reviewed here, it is imperative that access is granted to allow scientific research in this area to continue.

Katy Robjant, Central and North West London Mental Health Trust, London; Rita Hassan, Canterbury Christchurch University, Canterbury; Cornelius Katona, University of Kent, Canterbury, UK

Correspondence: Katy Robjant, Traumatic Stress Service, Clinical Treatment Centre, Maudsley Hospital, Denmark Hill, London SE5 8AZ, UK. Email: katy.robjant@thh.nhs.uk

First received 2 Apr 2008, final revision 17 Jul 2008, accepted 20 Aug 2008

\section{References}

1 United Nations High Commissioner for Refugees. Refugees by Numbers 2006 Edition. UNHCR, 2006.

2 Silove D, Steel Z, Watters C. Policies of deterrence and the mental health of asylum seekers. JAMA 2000; 284: 604-11.

3 Heath T, Jeffries R, Pearce S. Asylum statistics United Kingdom 2005. Home Office Statistical Bulletin 2006; 22 August: 1-90 (http:// www.homeoffice.gov.uk/rds/pdfs06/hosb1406.pdf).

4 Sinnerbrink I, Silove D, Field A, Steel Z, Manicavasagar V. Compounding of premigration trauma and postmigration stress in asylum seekers. J Psychol 1997; 131: 463-70.

5 Porter M, Haslam N. Predisplacement and postdisplacement factors associated with mental health of refugees and internally displaced persons. A meta-analysis. JAMA 2005; 294: 602-12.

6 Silove D, Steel Z, McGorry P, Mohan P. Psychiatric symptoms and living difficulties in Tamil asylum seekers: comparisons with refugees and immigrants. Acta Psychiatr Scand 1998; 97: 175-81.

7 Laban CJ, Gernaat H, Komproe IH, Schreuders BA, De Jong J. Impact of a long asylum procedure on the prevalence of psychiatric disorders in Iraqi asylum seekers in the Netherlands. J Nerv Ment Dis 2004; 192: 843-51.

8 Fazel M, Silove D. Detention of refugees. BMJ 2006; 332: 251-2.

9 Pourgourides CK, Sashidharan SP, Bracken PJ. A Second Exile: The Mental Health Implications of Detention of Asylum Seekers in the United Kingdom. North Birmingham NHS Trust, 1996.

10 Keller AS, Rosenfeld B, Trinh-Shvrin C, Meserve C, Sachs E, Leviss J, et al. Mental health of detained asylum seekers. Lancet 2003; 362: 1721-3.

11 Salinsky M. Detaining asylum seekers. BMJ 1997; 314: 456.

12 Koopowitz LF, Abhary S. Psychiatric aspects of detention: illustrative case studies. Aust N Z J Psychiatry 2004; 38: 495-500. 
13 Fazel M, Stein A. UK immigration law disregards the best interests of children. Lancet 2004; 363: 1749-50.

14 Steel Z, Silove D. Science and the common good: indefinite, non-reviewable mandatory detention of asylum seekers and the research imperative. Monash Bioeth Rev 2004; 23: 93-102.

15 Bracken P, Gorst-Unsworth C. The mental state of detained asylum seekers Psychiatr Bull 1991; 15: 657-9.

16 Arnold FW, Beeks M, Fluxman J, Katona C, de Zulueta F. Unmet medical needs in detention. BMJ Rapid Response 2006;

17 Sultan A, O'Sullivan K. Psychological disturbances in asylum seekers held in Iong term detention: a participant-observer account. Med J Austr 2001; 175: 593-6.

18 Thompson M, McGorry P. Maribyrnong Detention Centre Tamil survey. In The Mental Health and Wellbeing of On Shore Asylum Seekers in Australia (eds D. Silove, Z Steel): 27-30. University of New South Wales, Psychiatry Research and Teaching Unit, 1998.

19 Steel Z, Silove D, McGorry P, Mohan P. The Tamil survey. In The Mental Health and Wellbeing of On Shore Asylum Seekers in Australia (eds D Silove, Z Steel): 13-18. University of New South Wales, Psychiatry Research and Teaching Unit, 1998

20 Mollica RF, Caspi-Yavin Y, Bollini P, Truong T, Tor S, Lavelle J. The Harvard Trauma Questionnaire. Validating a cross-cultural instrument for measuring torture, trauma and posttraumatic stress disorder in Indochinese refugees. J Nerv Ment Dis 1992; 180: 111-6.

21 Mollica RF, Wyshak G, de Marneffe D, Khoun F, Lavelle J. Indochinese versions of the Hopkins Symptom Checklist-25: a screening instrument for the psychiatric care of refugees. Am J Psychiatry 1987; 144: 497-500.
22 Beiser M, Fleming JAE. Measuring psychiatric disorder among Southeast Asian refugees. Psychol Med 1986; 16: 627-39.

23 Steel Z, Silove D, Brooks R, Momartin S, Alzuhairi B, Susljik I. Impact of immigration detention and temporary protection on the mental health of refugees. Br J Psychiatry 2006; 188: 58-64.

24 Gandek B, Ware JE, Aaronson NK, Apolone G, Bjorner JB, Brazier JE, et al Cross-validation of item selection and scoring for the SF-12 Health Survey in nine countries: results from the IQOLA Project. International Quality of Life Assessment. J Clin Epidemiol 1998; 51: 1171-8.

25 Steel Z, Momartin S, Bateman C, Hafshejani A, Silove D. Psychiatric status of asylum seeker families held for a protracted period in a remote detention centre in Australia. Aust N Z J Public Health 2004; 28: 527-36.

26 Momartin S, Steel Z, Coello M, Aroche J, Silove D, Brooks R. A comparison of the mental health of refugees with temporary versus permanent protection visas. Med J Austr 2006; 185: 357-61.

27 Goldberg DP, Williams P. A User's Guide to the General Health Questionnaire. nferNelson, 1988.

28 Mares S, Jureidini J. Psychiatric assessment of children and families in immigration detention clinical, administrative and ethical issues. Aust $\mathrm{NZJ}$ Public Health 2004; 28: 520-6.

29 First MB, Spitzer RL, Gibbon M, Williams JBW. Structured Clinical Interview for DSM-V Axis I Disorders Administration Booklet. American Psychiatric Press, 1997.

30 Kaufman J, Birmaher B, Brent D, Rao U, Flynn C, Moreci P, et al. Schedule for affective disorders and schizophrenia for school age children - present and lifetime version (K-SADS-PL): initial reliability and validity data. J Am Acad Child Adolesc Psychiatry 1997; 36: 980-8.

\section{Psychiatrists in 19th-century fiction}

\section{The Rose and the Key (1871), J. Sheridan LeFanu}

\section{Fiona Subotsky}

The Rose and the Key is one of Sheridan Le Fanu's sensation novels, without any supernatural elements. It is set in England rather than Ireland, for better sales.

The heroine, Maud, is deceived into entering a lunatic asylum on the pretext that she is visiting the great house of Lady Mardykes. Evidence as to Maud's insanity has been gained by a strange evangelical called Elihu Lizard, who notes her playful claims of another identity and puts this down to delusion. Her mother, Lady Vernon, testifies to a suicide threat. Two sinister doctors, Dr Malkin the local practitioner and Dr Antomarchi an asylum administrator, collude with Lady Vernon, all hoping to gain by the prevention of Maud's marriage. Dr Damian, the upright but distant owner of the asylum, approves the papers but has not seen the patient or understood the family issues. Mr Tintern, the local magistrate, also eager to keep the approval of Lady Vernon, acts to endorse the arrangement legally.

Dr Michael Antomarchi has the key medical role. Obviously, he is 'foreign' and has a striking appearance - with 'marble feature, strange eyes, and coal-black square beard.' He is an expert in mesmerism, and controls the asylum (appropriately named 'Glareswood') with his fierce gaze and stern authority. He cows Maud into compliance by making her witness a forcible shower-bath followed by an emetic, which leaves the patient nearly dead. Le Fanu steps back from the narrative here, to point out that such a case was indeed investigated by the Lunacy commission, but that now such a practice 'is no longer countenanced by the faculty'.

Antomarchi is ambitious: he hopes to take over the asylum soon, and meanwhile is prepared to take money in excess from Lady Vernon. He wants to be 'monarch of all I survey'. The same expression was later used by Henry Maudsley in his autobiographical recollection of his time as medical superintendent at Cheadle, adapting a verse by William cowper:

'I am monarch of all I survey,

I am lord of the fool and the brute,

From the centre all round to the sphere,

My rite there is none to dispute.'

Although Maudsley achieved this, as is the nature in romances the 'brilliant rogue' Antomarchi has his evil plans foiled, and is compelled to leave the country, ending in 'sore straits'. 